\title{
Dynamics Analysis of Active Variable Stiffness Vibration Isolator for Whole-Spacecraft Systems Based on Nonlinear Output Frequency Response Functions
}

\author{
${\text { Kefan } \mathrm{Xu}^{1} \quad \text { Yewei Zhang }}^{1 \star(1)} \quad$ Yunpeng Zhu ${ }^{2} \quad$ Jian Zang $^{1} \quad$ Liqun Chen $^{3}$ \\ $\left({ }^{1}\right.$ College of Aerospace Engineering, Shenyang Aerospace University, Shenyang 110136, China) \\ $\left({ }^{2}\right.$ Department of Automatic Control and Systems Engineering, Sheffield University, Mapping Street, Sheffield \\ S1 $3 J D, U K)$ \\ $\left({ }^{3}\right.$ Harbin Institute of Technology, Shenzhen 518055, China)
}

Received 3 August 2020; revision received 12 October 2020; Accepted 14 October 2020; published online 5 November 2020

(C) The Author(s) 2020

\begin{abstract}
In order to improve the harsh dynamic environment experienced by heavy rockets during different external excitations, this study presents a novel active variable stiffness vibration isolator (AVS-VI) used as the vibration isolation device to reduce excessive vibration of the whole-spacecraft isolation system. The AVS-VI is composed of horizontal stiffness spring, positive stiffness spring, parallelogram linkage mechanism, piezoelectric actuator, acceleration sensor, viscoelastic damping, and PID active controller. Based on the AVS-VI, the generalized vibration transmissibility determined by the nonlinear output frequency response functions and the energy absorption rate is applied to analyze the isolation performance of the whole-spacecraft system with AVS-VI. The AVS-VI can conduct adaptive vibration suppression with variable stiffness to the whole-spacecraft system, and the analysis results indicate that the AVS-VI is effective in reducing the extravagant vibration of the whole-spacecraft system, where the vibration isolation is decreased up to above $65 \%$ under different acceleration excitations. Finally, different parameters of AVS-VI are considered to optimize the whole-spacecraft system based on the generalized vibration transmissibility and the energy absorption rate.
\end{abstract}

KEY WORDS Vibration isolation, Active variable stiffness vibration isolator, Nonlinear output frequency response functions (NOFRFs), Transmissibility

\section{Introduction}

In the field of aerospace engineering, harsh vibration environment has become a principal factor restricting the development of spacecraft and space exploration activities [1]. The extreme dynamic environment of heavy launch vehicles is one of the main reasons for the launch failure of the entire satellite system [2]. Therefore, reducing the effects of the satellite vibration environment is critical to improving the safety and reliability of satellite launches [3].

The whole-spacecraft vibration isolation usually requires a redesign of the adaptor with vibration isolation performance, but without changing the original structure of the satellite, or introduction of vibration isolation devices between the carrier rocket and the satellite [4]. A vibration isolator installed

\footnotetext{
* Corresponding author. E-mail: zhangyewei1218@126.com
} 
between the adapter and the payload to isolate the vibration load has been widely studied [5]. In general, the commonly used vibration isolation systems are mainly divided into passive [6-9], active [10-13], and semi-active $[14,15]$ ways. Simple equipment, high reliability, and requiring no external energy are usually considered as advantages of the passive vibration isolator. However, the application of passive vibration isolator is limited to low-frequency vibration isolation because it cannot be adjusted adaptively according to the changing environment [16]. It is difficult to solve the dense frequency and multi-mode problems using the existing adaptive and semi-active control methods. In this study, an active adaptive bionic vibration isolation mechanism is proposed to solve the key problem of low frequency, dense frequency, and multi-mode vibration in the launch process of heavy launch vehicle, so as to meet the requirements of the heavy launch vehicle development.

The biomimetic vibration isolation mechanism has become a hotspot in the research field of vibration control [17]. For example, Yoon et al. proposed an impact isolator activated by woodpecker to control unnecessary high-frequency mechanical excitation [18]. Many researchers began to study the mechanism of bionic vibration isolation and made some significant improvement [19-21]. Jing et al. proposed a variety of different types of bio-inspired vibration isolators and successfully applied them in engineering practice to achieve good vibration isolation effect [21-27]. However, most of the biomimetic vibration isolators are passive, and it is necessary to develop an active adaptive bionic isolator to achieve the vibration control effect with automatic adjustment.

In this study, the generalized vibration transmissibility developed based on the NOFRFs is used to analyze the isolation performance of the whole-spacecraft system with the AVS-VI. The concept of NOFRFs was proposed by Lang and Billings [28] and has been applied to solve many engineering problems by researchers [29-32]. For example, the NOFRFs have been applied to structural damage diagnosis and nonlinear system engineering [33-35]. Each order of NOFRFs is a one-dimensional frequency function and can be easily displayed and analyzed. Because the solution of NOFRFs is numerical, the stability analysis cannot be performed.

In this paper, we propose the AVS-VI for adaptive vibration reduction. Through a positive stiffness and negative stiffness structure (a parallel quadrilateral linkage implementation), we achieve the highstatic-low -dynamic stiffness (HSLDS) system. Combining viscous elastic elements with the PID active controller and piezoelectric actuator acting on the nonlinear negative stiffness structure, we develop a new type of efficient adaptive variable stiffness vibration isolator.

\section{The Whole-Spacecraft System with Active Variable Stiffness Vibration Isolator}

Figure 1 shows the equivalent model with active variable stiffness vibration isolator (AVS-VI), where $m_{\mathrm{a}}$ and $m_{\mathrm{b}}$ are the masses of the satellite and adapter system, respectively; $k_{i}$ and $c_{i}(i=$ a, b) are the coefficients of linear stiffness and damping of the whole-spacecraft system, respectively. The whole-spacecraft system can be simplified into a model with two degrees of freedom, which has been verified in our previous experiments [36]. A horizontal stiffness (HS) spring $k_{\mathrm{d}}$ acting on the positive stiffness (PS) spring $k_{\mathrm{c}}$ through the parallelogram linkage mechanism realizes a high-staticlow-dynamic stiffness (HSLDS) system. The high-speed piezoelectric actuator is added to the negative stiffness (NS) mechanism to $k_{\mathrm{d}}$ spring preload, $X_{0}$. The part of linkage mechanism of the negative stiffness was introduced in [37], and the PID active controller is added to the piezoelectric actuator, where the acceleration sensor is attached to the whole-spacecraft system to achieve the vibration control effect of automatic adjustment. Combined with high viscoelastic damping, a new high efficiency semiactive controller is developed. It is worth noting that the effect of gravity is ignored in this study.

Based on Newton's second law, the corresponding kinetic equations of the equivalent model of whole-spacecraft system can be established as follows:

$$
\begin{aligned}
& m_{\mathrm{a}} \ddot{x}_{\mathrm{a}}+k_{\mathrm{a}}\left(x_{\mathrm{a}}-x_{\mathrm{b}}\right)+c_{\mathrm{a}}\left(\dot{x}_{\mathrm{a}}-\dot{x}_{\mathrm{b}}\right)+m_{\mathrm{a}} \ddot{x}_{\mathrm{d}}=0 \\
& m_{\mathrm{b}} \ddot{x}_{\mathrm{b}}+k_{\mathrm{a}}\left(x_{\mathrm{b}}-x_{\mathrm{a}}\right)+c_{\mathrm{a}}\left(\dot{x}_{\mathrm{b}}-\dot{x}_{\mathrm{a}}\right)+k_{\mathrm{b}} x_{\mathrm{b}}+c_{\mathrm{b}} \dot{x}_{\mathrm{b}}+c_{\mathrm{c}} \dot{x}_{\mathrm{b}}+\left(k_{\mathrm{c}}-\frac{2 k_{\mathrm{d}}}{L} X_{0}\right) x_{\mathrm{b}}+m_{\mathrm{b}} \ddot{x}_{\mathrm{d}}=0
\end{aligned}
$$

where $x_{i}(i=\mathrm{a}, \mathrm{b})$ express the displacement of the whole-spacecraft system. $c_{\mathrm{c}}$ is the coefficient of viscoelastic damping, and $L$ is the length of the NS parallelogram linkage mechanism.

$$
X_{0}=-\left(K_{0} x_{\mathrm{a}}+K_{1} \dot{x}_{\mathrm{a}}+K_{2} \ddot{x}_{\mathrm{a}}\right)
$$




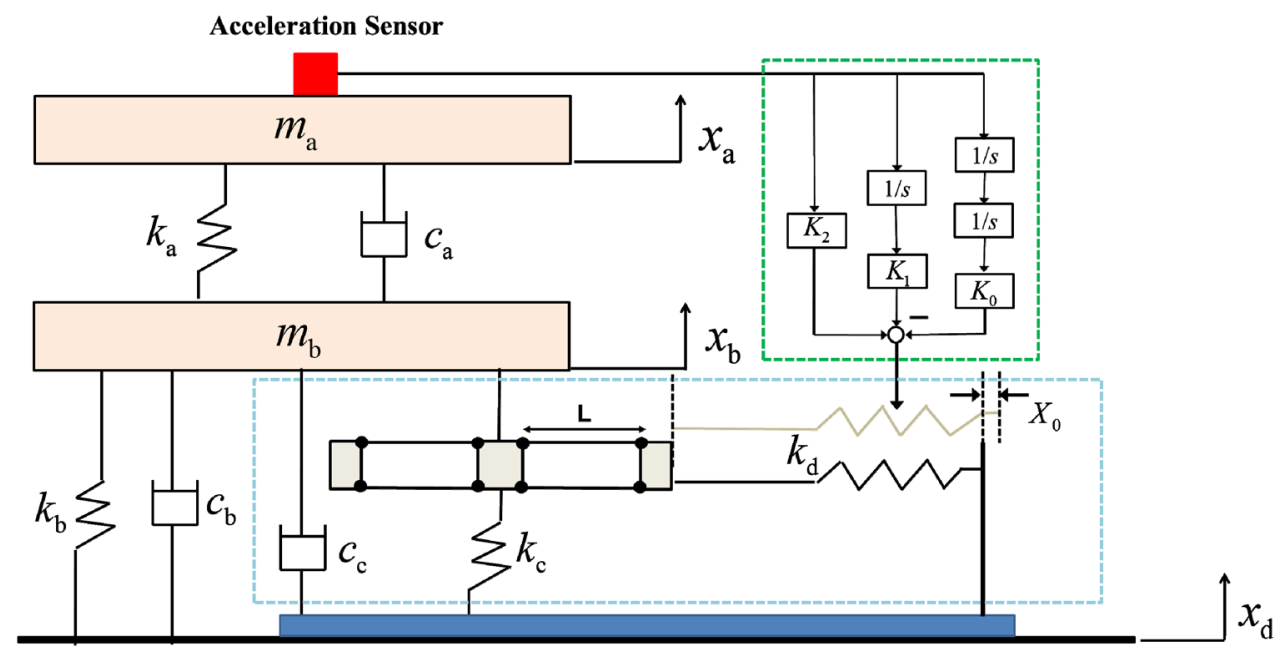

Fig. 1. Equivalent model of the whole-spacecraft system with AVS-VI

where $K_{i} \quad(i=0,1,2)$ represent the coefficients of PID active controller, and $x_{\mathrm{d}}$ is the acceleration excitation [38].

$$
\begin{aligned}
& x_{\mathrm{d}}=\frac{A_{\mathrm{d}}}{(2 \pi f)^{2}} \sin (2 \pi f t) \\
& \dot{x}_{\mathrm{d}}=\frac{A_{\mathrm{d}}}{2 \pi f} \cos (2 \pi f t) \\
& \ddot{x}_{\mathrm{d}}=-A_{\mathrm{d}} \sin (2 \pi f t)
\end{aligned}
$$

\section{Analysis Method on Account of the Transmissibility of NOFRFs}

In the frequency domain, the output spectra of a nonlinear system $X(j \omega)_{\mathrm{AVS}-\mathrm{VI}}$ can be expressed as the sum of the $n$-th order output frequency response [39].

$$
X(\mathrm{j} \omega)_{\mathrm{AVS}-\mathrm{VI}}=\sum_{n=1}^{N} X_{n}(\mathrm{j} \omega)_{\mathrm{AVS}-\mathrm{VI}}
$$

where $N$ is the maximum order of the nonlinear system

$$
X_{n}(\mathrm{j} \omega)_{\mathrm{AVS}-\mathrm{VI}}=\frac{1}{2^{n}} \sum_{\omega_{k_{1}}+\cdots+\omega_{k_{n}}=\omega} H_{n}\left(\mathrm{j} \omega_{k_{1}}, \ldots, \mathrm{j} \omega_{k_{n}}\right)_{\mathrm{AVS}-\mathrm{VI}} A_{\mathrm{d}}\left(\mathrm{j} \omega_{k_{1}}\right) \cdots A_{\mathrm{d}}\left(\mathrm{j} \omega_{k_{n}}\right)
$$

and

$$
A_{\mathrm{d}}(\mathrm{j} \omega)= \begin{cases}\left|A_{\mathrm{d}}\right| \mathrm{e}^{\mathrm{j} \operatorname{sign}(k)} & \text { if } \omega \in\left\{k \omega_{f}, k= \pm 1\right\} \\ 0 & \text { otherwise }\end{cases}
$$

where $X(\mathrm{j} \omega)_{\mathrm{AVS}-\mathrm{VI}}$ and $A_{\mathrm{d}}(\mathrm{j} \omega)$ describe the output and input spectra of the nonlinear system, respectively, and $H_{n}\left(\mathrm{j} \omega_{k_{1}}, \ldots, \mathrm{j} \omega_{k_{n}}\right)$ AVS-VI represents the $n$-th order generalized frequency response functions (GFRFs) of the nonlinear system [39].

A new concept known as the NOFRFs, which over the GFRFs lies in their single dimension order functions, was presented by Lang and Billings [28]. Based on the acceleration excitation, this concept can be mathematically described as

$$
G_{n}^{H}(\mathrm{j} \omega)_{\mathrm{AVS}-\mathrm{VI}}=\frac{\frac{1}{2^{n}} \sum_{\omega_{k_{1}}+\cdots+\omega_{k_{n}}=\omega} H_{n}\left(\mathrm{j} \omega_{k_{1}}, \ldots, \mathrm{j} \omega_{k_{n}}\right)_{\mathrm{AVS}-\mathrm{VI}} A_{\mathrm{d}}\left(\mathrm{j} \omega_{k_{1}}\right) \cdots A_{\mathrm{d}}\left(\mathrm{j} \omega_{k_{n}}\right)}{\frac{1}{2^{n}} \sum_{\omega_{k_{1}}+\cdots+\omega_{k_{n}}=\omega} A_{\mathrm{d}}\left(\mathrm{j} \omega_{k_{1}}\right) \cdots A_{\mathrm{d}}\left(\mathrm{j} \omega_{k_{n}}\right)}(n=1, \ldots, N)
$$

with

$$
A_{\mathrm{d}_{n}}(\mathrm{j} \omega)=\frac{1}{2^{n}} \sum_{\omega_{k_{1}}+\cdots+\omega_{k_{n}}=\omega} A_{\mathrm{d}}\left(\mathrm{j} \omega_{k_{1}}\right) \cdots A_{\mathrm{d}}\left(\mathrm{j} \omega_{k_{n}}\right) \neq 0
$$


and rewrite the n-th order output spectra of nonlinear system as:

$$
X(\mathrm{j} \omega)_{\mathrm{AVS}-\mathrm{VI}}=\sum_{n=1}^{N} X_{n}(\mathrm{j} \omega)_{\mathrm{AVS}-\mathrm{VI}}=\sum_{n=1}^{N} G_{n}^{H}(\mathrm{j} \omega)_{\mathrm{AVS}-\mathrm{VI}} A_{\mathrm{d}_{n}}(\mathrm{j} \omega)
$$

In Eq. (9), $G_{n}^{H}(\mathrm{j} \omega)_{\text {AVS-VI }}$ express the $n$-th order NOFRFs of the nonlinear system, and $A_{\mathrm{d}_{n}}(\mathrm{j} \omega)$ can be described as the Fourier transform of $x_{\mathrm{d}}^{n}(t)$ [32].

$$
A_{\mathrm{d}_{n}}(\mathrm{j} \omega)=\operatorname{FFT}\left[x_{\mathrm{d}}^{n}(t)\right]
$$

The NOFRFs of the nonlinear system is equal to the GFRFs of the system [40].

$$
\begin{aligned}
& G_{n}^{H}\left(\mathrm{j}(-n+2 k) \omega_{f}\right)_{\mathrm{AVS}-\mathrm{VI}}=\frac{\frac{1}{2^{n}} H_{n}(\overbrace{\mathrm{j} \omega_{f}, \ldots, \mathrm{j} \omega_{f}}^{k} \overbrace{-\mathrm{j} \omega_{f}, \ldots,-\mathrm{j} \omega_{f}}^{n-{ }_{\mathrm{AVS}-\mathrm{VI}} C_{n}^{k}\left|A_{\mathrm{d}}\right|^{n} \mathrm{e}^{\mathrm{j}(-n+2 k)}}}{\frac{1}{2^{n} C_{n}^{k}\left|A_{\mathrm{d}}\right|^{n} \mathrm{e}^{\mathrm{j}(-n+2 k)}}} \\
& =H_{n}(\overbrace{\mathrm{j} \omega_{f}, \ldots, \mathrm{j} \omega_{f}}^{k}, \overbrace{-\mathrm{j} \omega_{f}, \ldots,-\mathrm{j} \omega_{f}}^{n-k})_{\mathrm{AVS}-\mathrm{VI}}
\end{aligned}
$$

and the input spectrum can be simplified as

$$
A_{\mathrm{d}_{n}}\left(\mathrm{j}(-n+2 k) \omega_{f}\right)=\frac{1}{2^{n}} C_{n}^{k}\left|A_{\mathrm{d}}\right|^{n} \mathrm{e}^{\mathrm{j}(-n+2 k)}
$$

Based on the output frequency response, the first-order harmonic of NOFRFs can be expressed as [41]:

$$
\begin{aligned}
X\left(\mathrm{j} \omega_{f}\right)_{\mathrm{AVS}-\mathrm{VI}} & =X_{1}\left(\mathrm{j} \omega_{f}\right)_{\mathrm{AVS}-\mathrm{VI}}+X_{3}\left(\mathrm{j} \omega_{f}\right)_{\mathrm{AVS}-\mathrm{VI}}+\cdots \\
& =G_{1}\left(\mathrm{j} \omega_{f}\right)_{\mathrm{AVS}-\mathrm{VI}} A_{\mathrm{d}_{1}}\left(\mathrm{j} \omega_{f}\right)+G_{3}\left(\mathrm{j} \omega_{f}\right)_{\mathrm{AVS}-\mathrm{VI}} A_{\mathrm{d}_{3}}\left(\mathrm{j} \omega_{f}\right)+\cdots
\end{aligned}
$$

In most cases, when the system reaches the fourth-order nonlinearity, the analysis based on NOFRFs can meet the accuracy requirements. The fourth-order output frequency response of the nonlinear system can be expressed as [42]:

$$
\begin{aligned}
X\left(\mathrm{j} \omega_{f}\right)_{\mathrm{AVS}-\mathrm{VI}} & =G_{1}^{H}\left(\mathrm{j} \omega_{f}\right)_{\mathrm{AVS}-\mathrm{VI}} A_{\mathrm{d}_{1}}\left(\mathrm{j} \omega_{f}\right)+G_{3}^{H}\left(\mathrm{j} \omega_{f}\right)_{\mathrm{AVS}-\mathrm{VI}} A_{\mathrm{d}_{3}}\left(\mathrm{j} \omega_{f}\right) \\
X\left(\mathrm{j} 2 \omega_{f}\right)_{\mathrm{AVS}-\mathrm{VI}} & =G_{2}^{H}\left(\mathrm{j} 2 \omega_{f}\right)_{\mathrm{AVS}-\mathrm{VI}} A_{\mathrm{d}_{2}}\left(\mathrm{j} 2 \omega_{f}\right)+G_{4}^{H}\left(\mathrm{j} 2 \omega_{f}\right)_{\mathrm{AVS}-\mathrm{VI}} A_{\mathrm{d}_{4}}\left(\mathrm{j} 2 \omega_{f}\right) \\
X\left(\mathrm{j} 3 \omega_{f}\right)_{\mathrm{AVS}-\mathrm{VI}} & =G_{3}^{H}\left(\mathrm{j} 3 \omega_{f}\right)_{\mathrm{AVS}-\mathrm{VI}} A_{\mathrm{d}_{3}}\left(\mathrm{j} 3 \omega_{f}\right) \\
X\left(\mathrm{j} 4 \omega_{f}\right)_{\mathrm{AVS}-\mathrm{VI}} & =G_{4}^{H}\left(\mathrm{j} 4 \omega_{f}\right)_{\mathrm{AVS}-\mathrm{VI}} A_{\mathrm{d}_{4}}\left(\mathrm{j} 4 \omega_{f}\right)
\end{aligned}
$$

The generalized vibration transmissibility is obtained by the root-mean-square processing of the fourth-order harmonics of the nonlinear system [43]:

$$
\operatorname{Tran}_{x}=\frac{\sqrt{\left\|X\left(\mathrm{j} \omega_{f}\right)\right\|_{\mathrm{AVS}-\mathrm{VI}}^{2}+\left\|X\left(\mathrm{j} 2 \omega_{f}\right)\right\|_{\mathrm{AVS}-\mathrm{VI}}^{2}+\left\|X\left(\mathrm{j} 3 \omega_{f}\right)\right\|_{\mathrm{AVS}-\mathrm{VI}}^{2}+\left\|X\left(\mathrm{j} 4 \omega_{f}\right)\right\|_{\mathrm{AVS}-\mathrm{VI}}^{2}}}{2 A_{\mathrm{d}}}
$$

\section{Effects of AVS-VI on Account of the Transmissibility of NOFRFs}

In this section, in order to analyze the effect of vibration reduction in the whole-spacecraft system, the generalized vibration transmissibility of NOFRFs is used for calculating the whole-spacecraft system with AVS-VI. The parameters and values of an equivalent model of the whole-spacecraft system with AVS-VI are presented in Table 1, which are calculated from [36, 37].

The influence of higher harmonics should not be neglected due to the nonlinearity of system in practical engineering. Therefore, this paper adopts the generalized vibration transmissibility of NOFRFs to analyze the whole-spacecraft system. The generalized vibration transmissibility of NOFRFs considers the higher harmonics to evaluate the isolation effect of AVS-VI. Figure. 2 compares the transmissibility of NOFRFs of the whole-spacecraft system with AVS-VI with different acceleration excitations. It can be seen that the transmissibility amplitude of the first-order formant decreases with the increase in acceleration excitation $A_{\mathrm{d}}$ because of the adaptive vibration control of AVS-VI. The whole-spacecraft system presents soft nonlinear characteristics, which can be seen from Fig. $2 \mathrm{~b}$.

Figure 3a,b compares the vibration reduction effects of isolator without and with only damping $c_{\mathrm{c}}$, and with AVS-VI based on the transmissibility of NOFRFs under the acceleration excitation of 
Table 1. Parameters of the whole-spacecraft system and the AVS-VI

\begin{tabular}{llll}
\hline Parameters & Values & Parameters & Values \\
\hline$m_{\mathrm{a}}$ & $60 \mathrm{~kg}$ & $k_{\mathrm{c}}$ & $5 \times 10^{6} \mathrm{~N} / \mathrm{m}$ \\
$k_{\mathrm{a}}$ & $1.8677 \times 10^{6} \mathrm{~N} / \mathrm{m}$ & $k_{\mathrm{d}}$ & $3 \times 10^{7} \mathrm{~N} / \mathrm{m}$ \\
$c_{\mathrm{a}}$ & $600 \mathrm{~N} \mathrm{~s} / \mathrm{m}$ & $c_{\mathrm{c}}$ & $600 \mathrm{~N} \mathrm{~s} / \mathrm{m}$ \\
$m_{\mathrm{b}}$ & $12 \mathrm{~kg}$ & $K_{0}$ & 50 \\
$k_{\mathrm{b}}$ & $2.1346 \times 10^{4} \mathrm{~N} / \mathrm{m}$ & $K_{1}$ & 0.012 \\
$c_{\mathrm{b}}$ & $20 \mathrm{~N} \mathrm{~s} / \mathrm{m}$ & $K_{2}$ & 0.01 \\
& & $L$ & $0.25 \mathrm{~m}$ \\
\hline
\end{tabular}

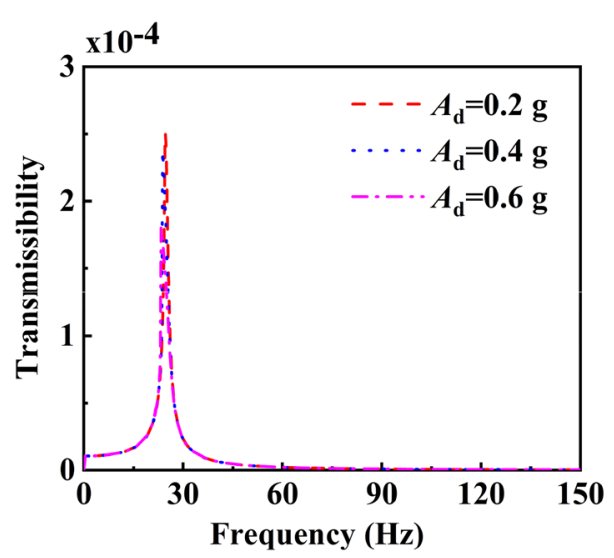

(a)

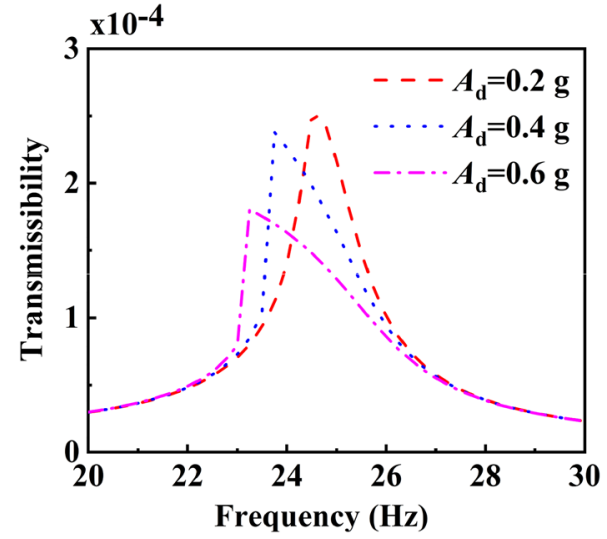

(b)

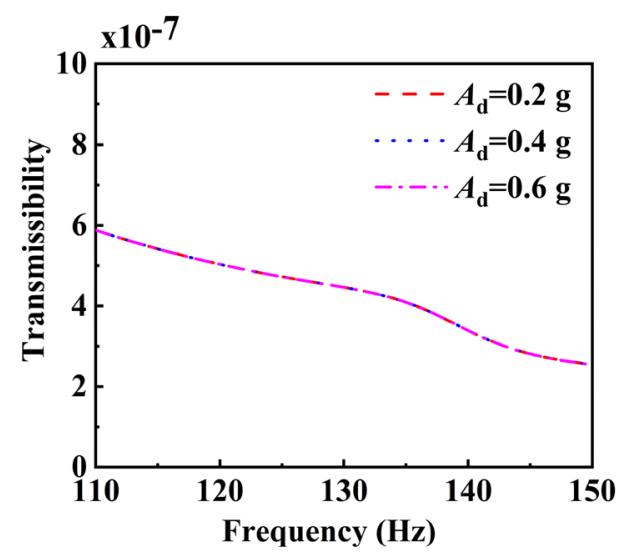

(c)

Fig. 2. Transmissibility of system and enlargement under different acceleration excitations $A_{\mathrm{d}}$

$A_{\mathrm{d}}=0.3 \mathrm{~g}$. It can be seen that the vibration suppression effect of the whole-spacecraft system with AVS-VI is obviously better than the whole-spacecraft system with only damping $c_{\mathrm{c}}$. The vibration reduction effects of PS-NS and AVS-VI are examined by Fig. 3c,d under the acceleration excitation of $A_{\mathrm{d}}=0.4 \mathrm{~g}$. It can be seen that the vibration suppression effect of the whole-spacecraft system with AVS-VI is obviously better than the whole-spacecraft system with PS-NS in terms of the first-order formant, while the transmissibility amplitudes of the second-order formant are almost unchanged.

In order to prove that AVS-VI can generate fast and large adaptive dynamic stiffness control. Figure 4 shows the transmissibility amplitudes curves of $x_{\text {a }}$ with different acceleration excitations of $A_{\mathrm{d}}=0.1 \mathrm{~g}, 0.2 \mathrm{~g}, 0.3 \mathrm{~g}, 0.4 \mathrm{~g}$, and $0.5 \mathrm{~g}$, respectively. It can be seen that with different acceleration excitation, the transmissibility amplitudes of the first-order formant of the whole-spacecraft system 


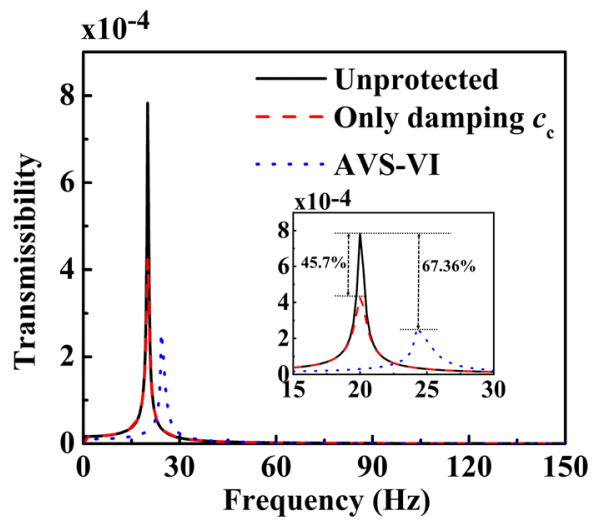

(a)

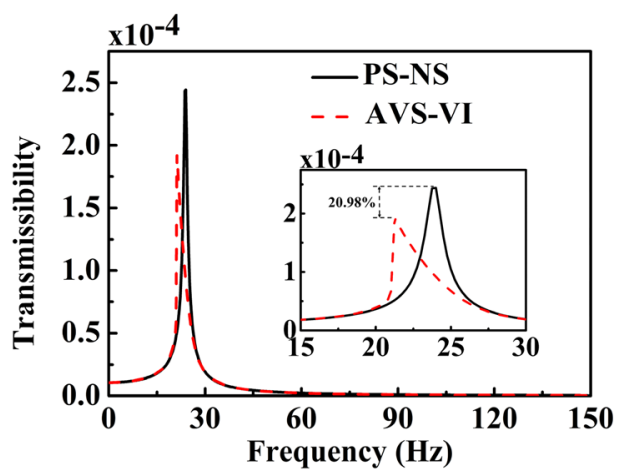

(c)

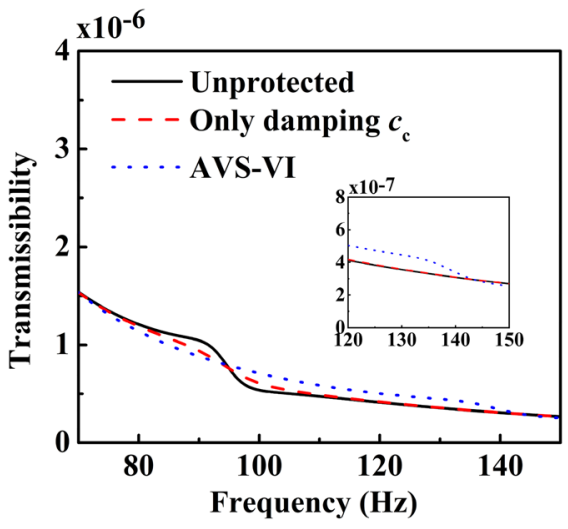

(b)

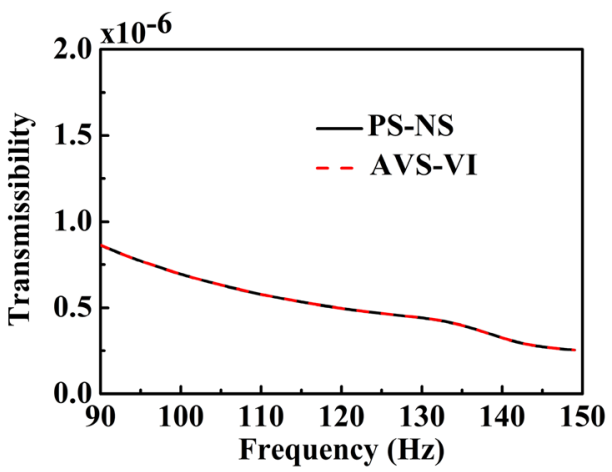

(d)

Fig. 3. Transmissibility response curves of $x_{\mathrm{a}}$ : without and with only damping $c_{\mathrm{c}}$, and with AVS-VI (a, b), with PS-NS and with AVS-VI $(\mathbf{c}, \mathbf{d})$

Table 2. Transmissibility amplitudes at the first-order formant with different acceleration excitations

\begin{tabular}{llllll}
\hline & $A_{\mathrm{d}}=0.1 \mathrm{~g}$ & $A_{\mathrm{d}}=0.2 \mathrm{~g}$ & $A_{\mathrm{d}}=0.3 \mathrm{~g}$ & $A_{\mathrm{d}}=0.4 \mathrm{~g}$ & $A_{\mathrm{d}}=0.5 \mathrm{~g}$ \\
\hline No AVS-VI $\left(x_{\mathrm{a}}\right)$ & 0.0007831 & 0.0007831 & 0.0007831 & 0.0007831 & 0.0007831 \\
With AVS-VI $\left(x_{\mathrm{a}}\right)$ & 0.000251 & 0.0002555 & 0.0002638 & 0.000245 & 0.0002184 \\
Decreased $(\%)$ & 67.8 & 67.4 & 66.3 & 68 & 72.1 \\
\hline
\end{tabular}

also change, while the transmissibility amplitudes of the second-order formant are almost unchanged. Table 2 details the decreases of transmissibility amplitudes at the first-order formant without and with AVS-VI under different acceleration excitations. It can be concluded that under different acceleration excitations, the decrease in vibration isolation of AVS-VI is up to above $65 \%$, and the natural frequency of the whole-spacecraft system also changes.

\section{Parameter Analysis Based on the Transmissibility}

Parameter changes are crucial in the structure design of vibration suppression. In order to study the effects of AVS-VI parameters on the generalized transmissibility of the whole-spacecraft system, the influence of each parameter on the vibration reduction performance is investigated by changing one parameter with other parameters unchanged. Figure 5 shows the transmissibility amplitudes curves of the whole-spacecraft system with different parameters, i.e., damping $c_{\mathrm{c}}$, positive stiffness $k_{\mathrm{c}}$, and negative stiffness $k_{\mathrm{d}}$, of AVS-VI under $A_{\mathrm{d}}=0.2 \mathrm{~g}$, respectively. It can be seen that the transmissibility amplitudes of the first-/second-order formant clearly decrease with the increase in damping $c_{\mathrm{c}}$, and 


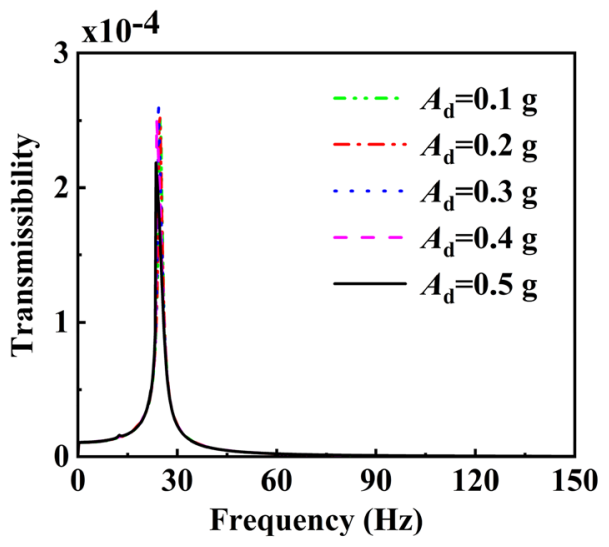

(a)

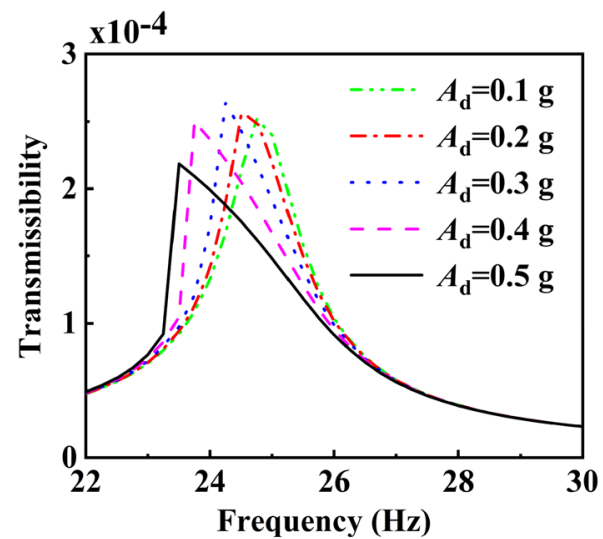

(b)

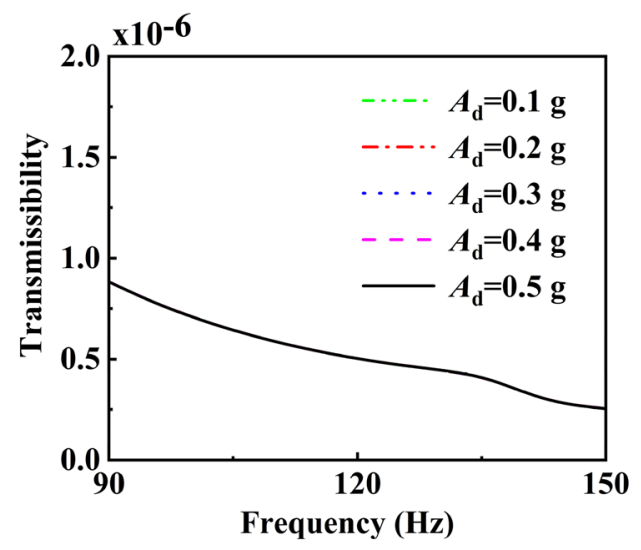

(c)

Fig. 4. Transmissibility amplitude curves of $x_{\mathrm{a}}$ with different acceleration excitations $A_{\mathrm{d}}$

positive stiffness $k_{\mathrm{c}}$, respectively. As the negative stiffness $k_{\mathrm{d}}$ increases, the transmissibility amplitudes of the first-order formant clearly decrease, but those of the second-order formant are almost un-changed.

Figure 6 shows the transmissibility amplitudes curves of the whole-spacecraft system with different active controller parameters $P, I$, and $D$. It can be seen that as the active controller $P$ and $I$ increase, the transmissibility amplitudes of the first-order formant clearly decrease, those of the second-order formant have no clear change, and the natural frequency of the whole-spacecraft system obviously decreases.

\section{Energy Absorption Analysis}

In order to examine the effectiveness of AVS-VI in reducing the excessive vibration from the wholespacecraft system, the percentage of energy absorption $\eta_{\mathrm{AVS}-\mathrm{VI}}(t)$ is proposed, which can be expressed as

$$
\begin{aligned}
\eta_{\mathrm{AVS}-\mathrm{VI}}(t) & =\frac{E_{\text {Unprotected }}(t)-E_{\mathrm{AVS}-\mathrm{VI}}(t)}{E_{\text {Unprotected }}(t)} \times 100 \% \\
E_{\mathrm{a}}(t) & =\frac{1}{2} m_{\mathrm{a}} \dot{x}_{\mathrm{a}}^{2}+\frac{1}{2} k_{\mathrm{a}}\left(x_{\mathrm{a}}-x_{\mathrm{b}}\right)^{2}+c_{\mathrm{a}} \int_{0}^{t}\left[\left(\dot{x}_{\mathrm{a}}-\dot{x}_{\mathrm{b}}\right)\right] \mathrm{d} t \\
E_{\mathrm{b}}(t) & =\frac{1}{2} m_{\mathrm{b}} \dot{x}_{\mathrm{b}}^{2}+\frac{1}{2} k_{\mathrm{b}}\left(x_{\mathrm{b}}-x_{\mathrm{d}}\right)^{2}+c_{\mathrm{b}} \int_{0}^{t}\left[\left(\dot{x}_{\mathrm{b}}-\dot{x}_{\mathrm{d}}\right)\right] \mathrm{d} t \\
E_{\text {total }}(t) & =E_{\mathrm{a}}(t)+E_{\mathrm{b}}(t)
\end{aligned}
$$




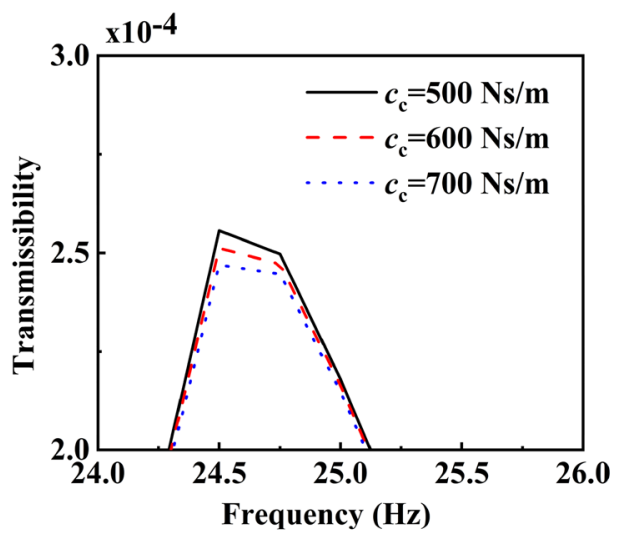

(a)

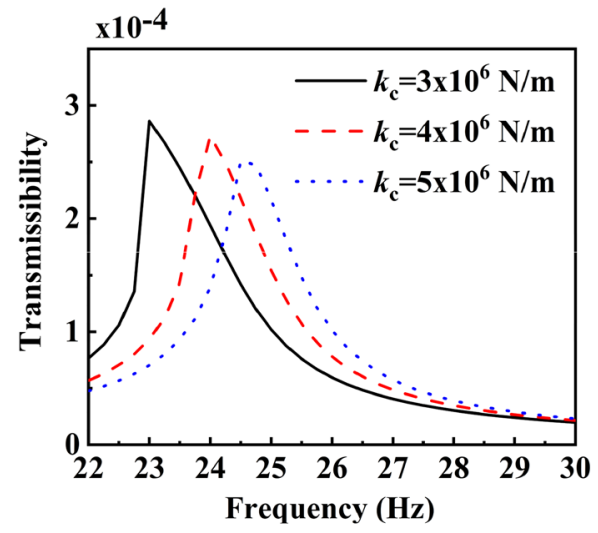

(c)

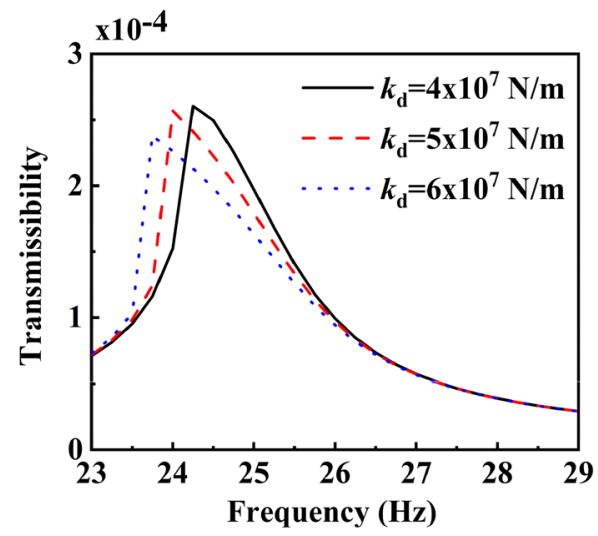

(e)

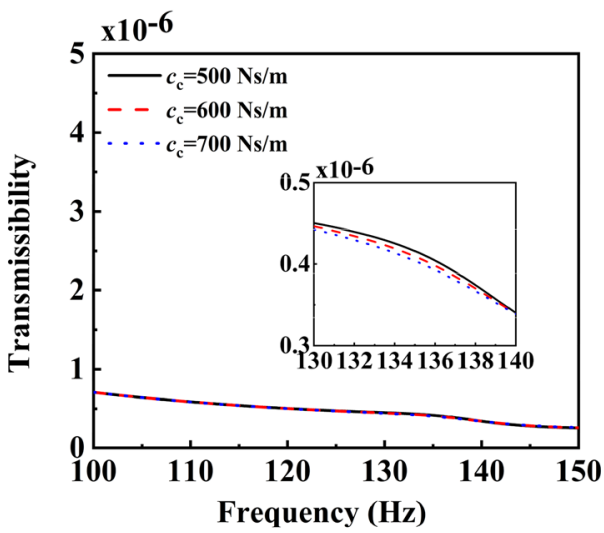

(b)

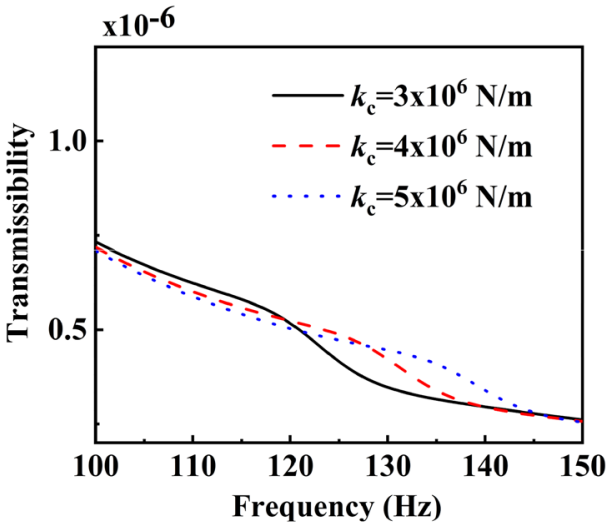

(d)

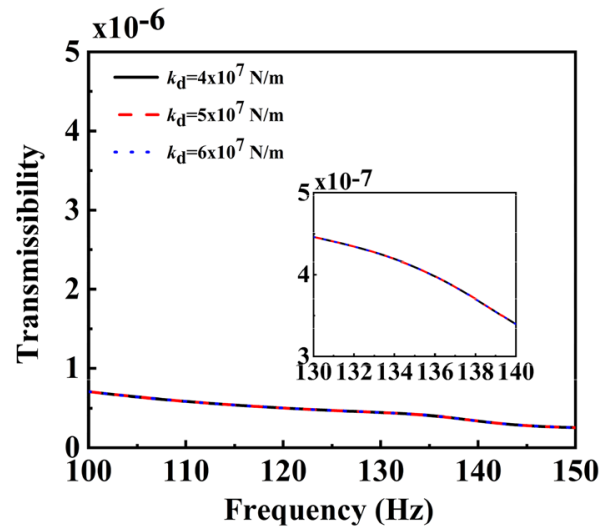

(f)

Fig. 5. Transmissibility amplitude curves of $x_{\mathrm{a}}$ with different parameters changing: damping $c_{\mathrm{c}}$, positive stiffness $k_{\mathrm{c}}$, negative stiffness $k_{\mathrm{d}}$ 


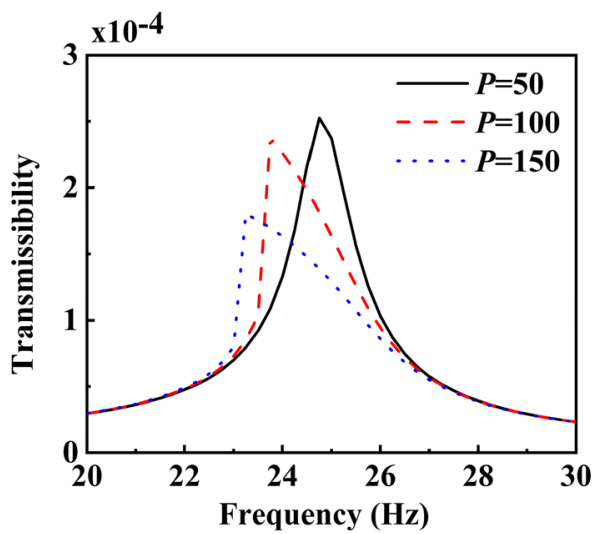

(a)

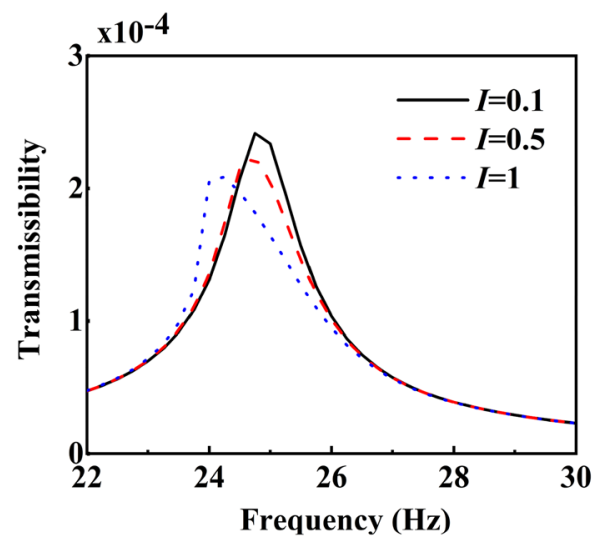

(c)

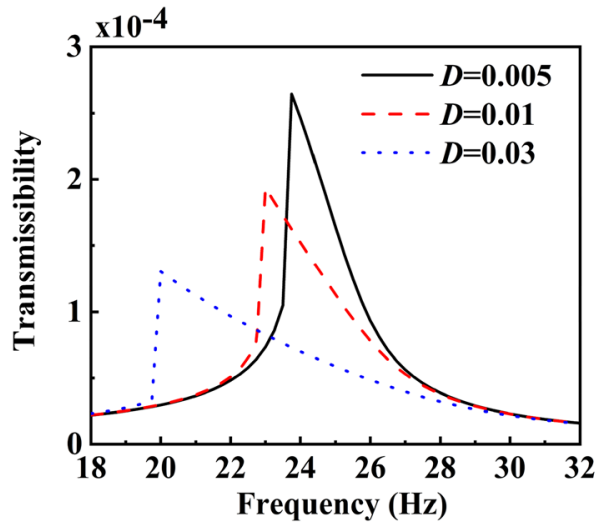

(e)

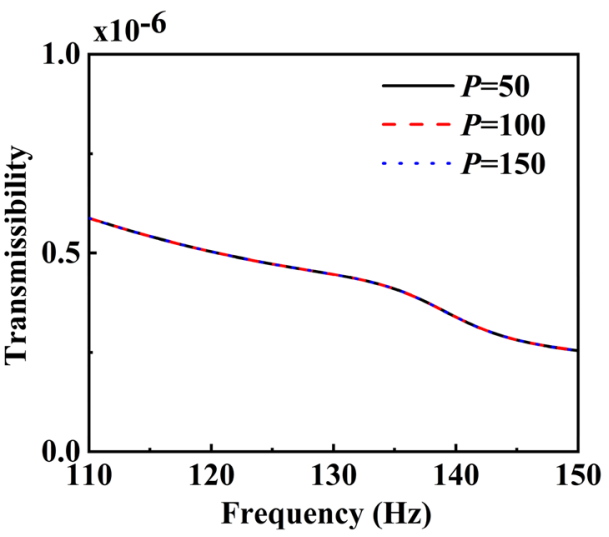

(b)

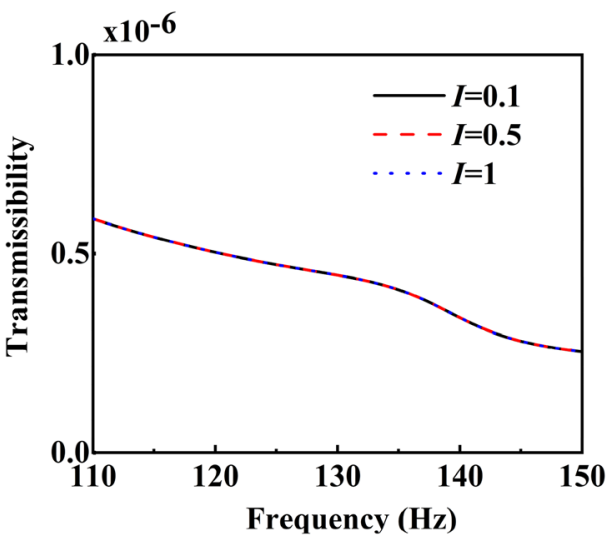

(d)

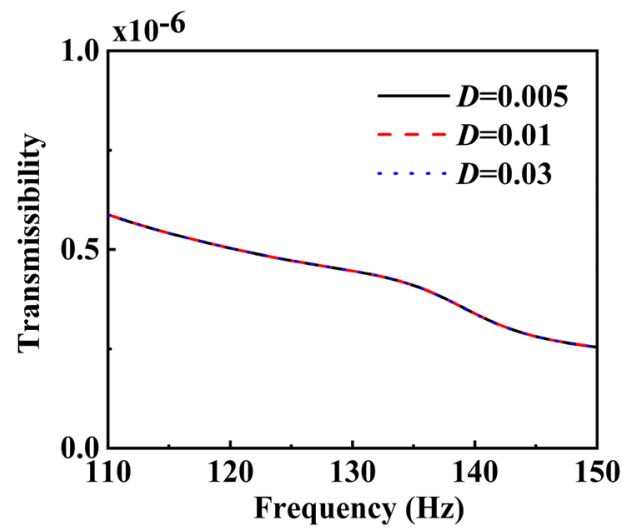

(f)

Fig. 6. Transmissibility amplitude curves of the first-/second-order formant of $x_{\mathrm{a}}$ with different active controller parameters, $P, I$, and $D$ 


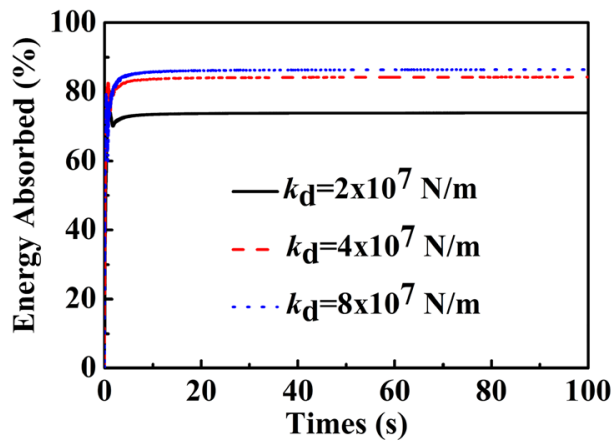

(a)

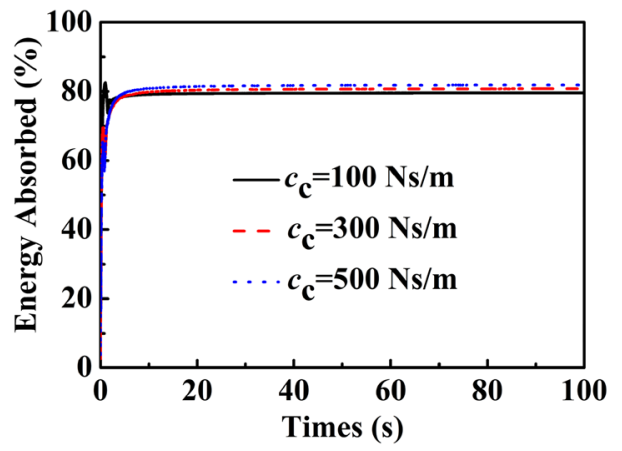

(c)

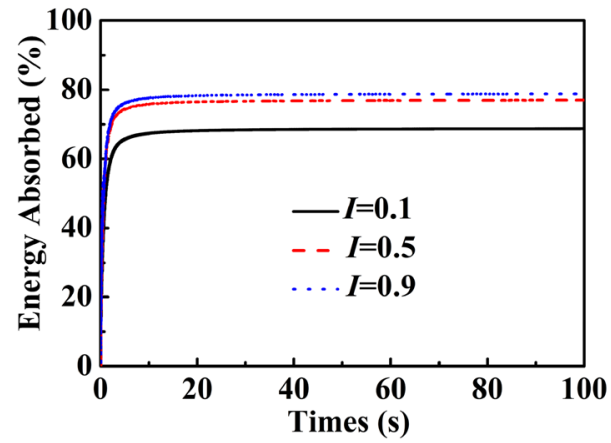

(e)

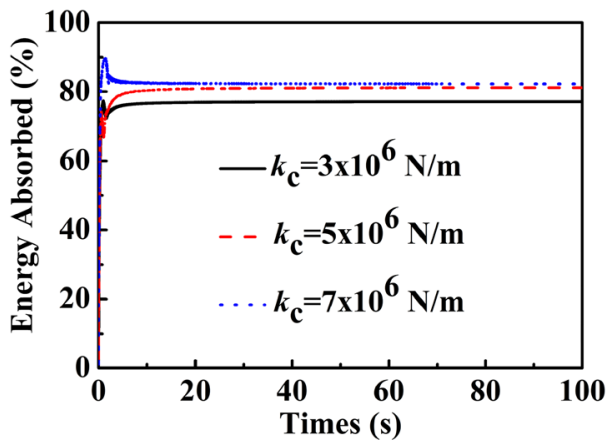

(b)

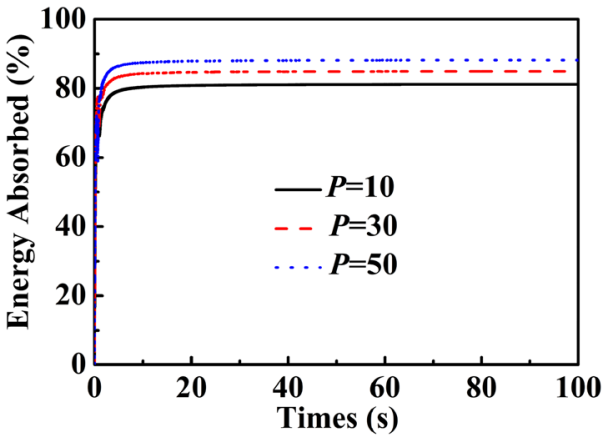

(d)

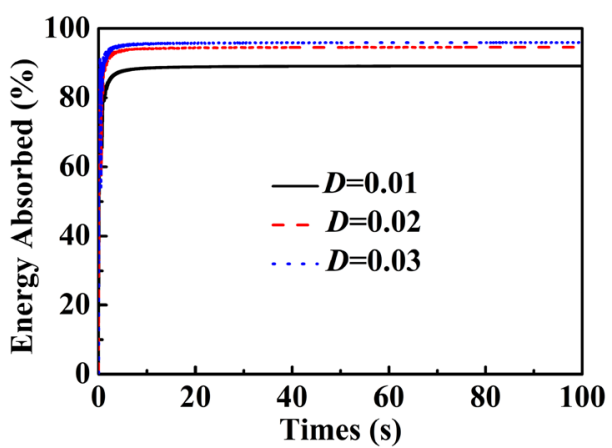

(f)

Fig. 7. Percentage of energy absorption of AVS-VI under different parameters: $k_{\mathrm{d}}(\mathbf{a}), k_{\mathrm{c}}(\mathbf{b}), c_{\mathrm{c}}(\mathbf{c}), P(\mathbf{d}), I(\mathbf{e})$, and $D$ (f)

where $E_{i}(t)(i=\mathrm{a}, \mathrm{b})$ represent the energy absorbed by the satellite and adapter system, respectively, while $\frac{1}{2} m_{\mathrm{a}} \dot{x}_{\mathrm{a}}^{2}, \frac{1}{2} k_{\mathrm{a}}\left(x_{\mathrm{a}}-x_{\mathrm{b}}\right)^{2}$, and $c_{\mathrm{a}} \int_{0}^{t}\left(\dot{x}_{\mathrm{a}}-\dot{x}_{\mathrm{b}}\right) \mathrm{d} t$ represent the kinetic, potential, and dissipated energies of damping of the satellite system, respectively.

The effects of different parameters of the AVS-VI, i.e., horizontal stiffness $k_{\mathrm{d}}$, positive stiffness $k_{\mathrm{c}}$, viscoelastic damping $c_{\mathrm{c}}$, active controller parameters $P, I$, and $D$ on the percentage of energy absorption are examined by Fig. 7. It can be seen that the percentage of energy absorption of the first-order formant clearly decreases as the horizontal stiffness $k_{\mathrm{d}}$, positive stiffness $k_{\mathrm{c}}$, viscoelastic damping $c_{\mathrm{c}}$, active controller parameters $P, I$, and $D$ increase, and the influences of horizontal stiffness $k_{\mathrm{d}}$ and stiffness $k_{\mathrm{c}}$ are more distinct than that of viscoelastic damping $c_{\mathrm{c}}$. Therefore, from the energy 
perspective, the AVS-VI also has a good vibration suppression effect and fast adaptive dynamic stiffness control.

\section{Conclusions}

In this study, a novel AVS-VI is proposed to reduce excessive vibration of the whole-spacecraft isolation system. The whole-spacecraft system is described as two-degree-of-freedom system, and the vibration isolation device composed of a horizontal stiffness spring, positive stiffness spring, parallelogram linkage mechanism, piezoelectric actuator, acceleration sensor, viscoelastic damping, and PID active controller is considered. The generalized vibration transmissibility of NOFRFs and the energy absorption rate are used to analyze and design the whole-spacecraft system with AVS-VI. The following conclusions are drawn from the investigation:

(1) The design and optimization of AVS-VI are completed in the design stage, which can realize a fast and large dynamic stiffness control of vibration isolator according to the changing external excitations.

(2) The AVS-VI is effective in reducing the extravagant vibration of the whole-spacecraft system. The decrease in vibration isolation of the AVS-VI is up to above $65 \%$ under different acceleration excitations.

(3) The isolation performance of the whole-spacecraft system is assessed by the transmissibility of NOFRFs. Compared with the vibration reduction in simple viscoelastic damping and PS-NS, the AVS-VI shows a flexible and better isolation performance in the vibration isolation of the wholespacecraft system.

(4) With suitably adjusted parameters such as positive stiffness, damping, active controller PID coefficient, and negative stiffness, the vibration reduction effects of AVS-VI can be improved.

Acknowledgements. This work was supported by the National Natural Science Foundation of China (Project Nos. 12022213, 11772205 and 11902203), the Scientific Research Fund of Liaoning Provincial Education Department (No. L201703), the Program of Liaoning Revitalization Talents (XLYC1807172), and the Training Project of Liaoning Higher Education Institutions in Domestic and Overseas (Nos. 2018LNGXGJWPY-YB008).

Open Access This article is licensed under a Creative Commons Attribution 4.0 International License, which permits use, sharing, adaptation, distribution and reproduction in any medium or format, as long as you give appropriate credit to the original author(s) and the source, provide a link to the Creative Commons licence, and indicate if changes were made. The images or other third party material in this article are included in the article's Creative Commons licence, unless indicated otherwise in a credit line to the material. If material is not included in the article's Creative Commons licence and your intended use is not permitted by statutory regulation or exceeds the permitted use, you will need to obtain permission directly from the copyright holder. To view a copy of this licence, visit http://creativecommons.org/ licenses/by/4.0/.

\section{References}

[1] Liu LK, Zheng GT, Huang WH. Octo-strut vibration isolation platform and its application to whole spacecraft vibration isolation. J Sound Vib. 2006;289(4):726-44.

[2] Fei H, Song E, Ma X, Jiang DW. Research on whole-spacecraft vibration isolation based on predictive control. Procedia Eng. 2011;16:467-76.

[3] Tan LJ, Fang B, Zhang JJ, Huang WH. Nonlinear dynamic analysis for the new whole-spacecraft passive vibration isolator. Appl Mech Mater. 2013;300:1231-4.

[4] Wilke PS, Johnson CD, Fosness ER. Whole-Spacecraft passive launch isolation. J Spacecr Rockets. 1998;35(5):690-4.

[5] Zhang YW, Fang B, Chen Y. Vibration isolation performance evaluation of the discrete whole-spacecraft vibration isolation platform for flexible spacecrafts. Meccanica. 2012;47(3):1185-95.

[6] Chen JE, Zhang W, Yao MH, Liu J, Sun M. Vibration reduction in truss core sandwich plate with internal nonlinear energy sink. Compos Struct. 2018;193:180-8.

[7] Zhang YW, Lu YN, Zhang W, Teng YY, Yang HH, Yang TZ, Chen LQ. Nonlinear energy sink with inerter. Mech Syst Signal Process. 2019;125(15):52-64.

[8] Lu ZQ, Gu DH, Ding H, Lacarbonara W, Chen LQ. Nonlinear vibration isolation via a circular ring. Mech Syst Signal Process. 2020;136:106490.

[9] Chen JE, He W, Zhang W, Yao MH, Liu J, Sun M. Vibration suppression and higher branch responses of beam with parallel nonlinear energy sinks. Nonlinear Dyn. 2018;91(2):885-904. 
[10] Fei HZ, Zheng GT, Liu ZG. An investigation into active vibration isolation based on predictive control: part I: energy source control. J Sound Vib. 2006;296(1):195-208.

[11] Song ZG, Li FM. Aeroelastic analysis and active flutter control of nonlinear lattice sandwich beams. Nonlinear Dyn. 2014;76(4):57-68.

[12] Chen T, Wen H, Hu HY, Jin DP. Output consensus and collision avoidance of a team of flexible spacecraft for on-orbit autonomous assembly. Acta Astronaut. 2016;121:271-81.

[13] Paul S, Yu W. A method for bidirectional active control of structures. J Vib Control. 2018;4(15):3400-17.

[14] Wang Y, Ding H, Chen LQ. Averaging analysis on a semi-active inerter-based suspension system with relative-acceleration-relative-velocity control. J Vib Control. 2020;26:1199-215.

[15] Alujevic N, Cakmak D, Wolf H, Jokic M. Passive and active vibration isolation systems using inerter. J Sound Vib. 2018;418:163-83.

[16] Ding H, Chen LQ. Nonlinear vibration of a slightly curved beam with quasi-zero-stiffness isolators. Nonlinear Dyn. 2019;95(1):2367-82.

[17] Pan HH, Jing XJ, Sun WC, Gao HJ. A bioinspired dynamics-based adaptive tracking control for nonlinear suspension systems. IEEE Trans Control Syst Technol. 2018;26:903-14.

[18] Yoon SH, Roh JE, Kim KL. Woodpecker-inspired shock isolation by microgranular bed. J Phys D. 2009;42(3):035501.

[19] Fu HL, Sharifkhodaei Z, Aliabadi F. A bio-inspired host-parasite structure for broadband vibration energy harvesting from low-frequency random sources. Appl Phys Lett. 2019;114(14):143901.

[20] Li HT, Yang HT, Kwon IY, Ly FS. Bio-inspired passive base isolator with tuned mass damper inerter for structural control. Smart Mater Struct. 2019;28:105008.

[21] Wang X, Yue XK, Dai HH, Yuan JP. Vibration suppression for post-capture spacecraft via a novel bioinspired Stewart isolation system. Acta Astronaut. 2020;168:1-22.

[22] Hu F, Jing XJ. A 6-DOF passive vibration isolator based on Stewart structure with X-shaped legs. Nonlinear Dyn. 2018;91(1):157-85.

[23] Wang Y, Jing XJ, Guo YQ. Nonlinear analysis of a bio-inspired vertically asymmetric isolation system under different structural constraints. Nonlinear Dyn. 2019;95(1):445-64.

[24] Jing XJ, Zhang LL, Feng X, Sun B, Li QK. A novel bio-inspired anti-vibration structure for operating hand-held jackhammers. Mech Syst Signal Process. 2019;118:317-39.

[25] Dai HH, Jing XJ, Wang Y, Yue XK, Yuan JP. Post-capture vibration suppression of spacecraft via a bio-inspired isolation system. Mech Syst Signal Process. 2018;105:214-40.

[26] Dai HH, Jing XJ, Sun C, Wang Y, Yue XK. Accurate modeling and analysis of a bio-inspired isolation system: with application to on-orbit capture. Mech Syst Signal Process. 2018;109:111-33.

[27] Jiang GQ, Jing XJ, Guo YQ. A novel bio-inspired multi-joint anti-vibration structure and its nonlinear HSLDS properties. Mech Syst Signal Process. 2020;138:106552.

[28] Lang ZQ, Billings SA. Energy transfer properties of non-linear systems in the frequency domain. Int J Control. 2005;78(5):345-62.

[29] Peng ZK, Lang ZQ, Billings SA. Analysis of locally nonlinear mdof systems using nonlinear output frequency response functions. J Vib Acoust. 2009;131(5):051007-1.

[30] Peng ZK, Lang ZQ, Billings SA, Tomlinson GR. Comparisons between harmonic balance and nonlinear output frequency response function in nonlinear system analysis. J Sound Vib. 2008;311:56-73.

[31] Yang K, Zhang YW, Ding H, Chen LQ. The transmissibility of nonlinear energy sink based on nonlinear output frequency-response functions. Commun Nonlinear Sci. 2017;44:184-92.

[32] Bayma RS, Zhu YP, Lang ZQ. The analysis of nonlinear systems in the frequency domain using nonlinear output frequency response functions. Automatica. 2018;94:452-7.

[33] Huang HL, Mao HY, Mao HL, Zheng WX, Huang ZF, Li XX, Wang XH. Study of cumulative fatigue damage detection for used parts with nonlinear output frequency response functions based on NARMAX modelling. J Sound Vib. 2017;411:75-877.

[34] Mao HL, Tang WL, Huang Y, Yuan DH, Huang ZF, Li XX, Zheng WX, Ma SH. The construction and comparison of damage detection index based on the nonlinear output frequency response function and experimental analysis. J Sound Vib. 2018;427:82-94.

[35] Liu Y, Zhao YL, Li JT, Ma H, Yang Q, Yan XX. Application of weighted contribution rate of nonlinear output frequency response functions to rotor rub-impact. Mech Syst Signal Process. 2020;136:106518.

[36] Yang K, Zhang YW, Ding H, Yang TZ, Li Y, Chen LQ. Nonlinear energy sink for whole-spacecraft vibration reduction. J Vib Acoust. 2017;139:021011-1.

[37] Churchill CB, Shahan DW, Smith SP, Keefe AC, Mcknight GP. Dynamically variable negative stiffness structures. Sci Adv. 2016;2(2):e1500778. 
[38] Zhang YW, Lu YN, Chen LQ. Energy harvesting via nonlinear energy sink for whole-spacecraft. Sci China Technol Sci. 2019;62(9):1483-91.

[39] Lang ZQ, Billings SA. Output frequencies of nonlinear systems. Int J Control. 1997;67:713-30.

[40] Peng ZK, Lang ZQ, Billings SA. Crack detection using nonlinear output frequency response functions. J Sound Vib. 2007a;301:777-88.

[41] Zhu YP, Lang ZQ. Analysis of output response of nonlinear systems using nonlinear output frequency response functions. In: UKACC International conference on control. 2016.

[42] Peng ZK, Lang ZQ, Billings SA. Resonances and resonant frequencies for a class of nonlinear systems. J Sound Vib. 2007b;300(3):993-1014.

[43] Zhang YW, Xu KF, Zang J, Ni ZY, Zhu YP, Chen LQ. Dynamic design of a nonlinear energy sink with NiTiNOL-steel wire ropes based on nonlinear output frequency response functions. Appl Math Mech-Engl. 2019;40:791-1804. 